\title{
Myeloperoxidase produces nitrating oxidants in vivo
}

\author{
Joseph P. Gaut, ${ }^{1}$ Jaeman Byun, ${ }^{1}$ Hung D. Tran, ${ }^{1}$ \\ Wendy M. Lauber, ${ }^{2}$ James A. Carroll, ${ }^{2}$ Richard S. Hotchkiss, ${ }^{3}$ \\ Abderrazzaq Belaaouaj, ${ }^{1,4}$ and Jay W. Heinecke ${ }^{1,5}$
} ${ }^{1}$ Department of Medicine, Washington University School of Medicine, St. Louis, Missouri, USA
${ }^{2}$ Pharmacia Corp., St. Louis, Missouri, USA
${ }^{3}$ Department of Anesthesiology,
${ }^{4}$ Department of Molecular Microbiology, and
${ }^{5}$ Department of Molecular Biology and Pharmacology, Washington University School of Medicine, St. Louis, Missouri, USA
Address correspondence to: Jay W. Heinecke, Division of Atherosclerosis, Nutrition and Lipid Research, Box 8046,
660 South Euclid Avenue, St. Louis, Missouri 63110, USA. Fax: (314) 362-0811; E-mail: heinecke@im.wustl.edu.

Joseph P. Gaut and Jaeman Byun contributed equally to this work.

Received for publication January 10, 2002, and accepted in revised form April 5, 2002.

\begin{abstract}
Despite intense interest in pathways that generate reactive nitrogen species, the physiologically relevant mechanisms for inflammatory tissue injury remain poorly understood. One possible mediator is myeloperoxidase, a major constituent of neutrophils, monocytes, and some populations of macrophages. The enzyme uses hydrogen peroxide and nitrite to generate 3-nitrotyrosine in vitro. To determine whether myeloperoxidase produces nitrating intermediates in vivo, we used isotope dilution gas chromatography/mass spectrometry to quantify 3-nitrotyrosine in two models of peritoneal inflammation: mice infected with Klebsiella pneumoniae and mice subjected to cecal ligation and puncture. Both models developed an intense neutrophil inflammatory response, and the inflammatory fluid contained markedly elevated levels of 3-chlorotyrosine, a marker of myeloperoxidase action. In striking contrast, 3-nitrotyrosine levels rose only in the mice infected with $K$. pneumoniae. Levels of total nitrite and nitrate were 20 -fold higher in mice injected with $K$. pneumoniae than in mice subjected to cecal ligation and puncture. Levels of 3-nitrotyrosine failed to increase in mice infected with $K$. pneumoniae that lacked functional myeloperoxidase. Our observations provide strong evidence that myeloperoxidase generates reactive nitrogen species in vivo and that it operates in this fashion only when nitrite and nitrate become available.
\end{abstract}

This article was published online in advance of the print edition. The date of publication is available from the JCI website, http://www.jci.org. J. Clin. Invest. 109:1311-1319 (2002). doi:10.1172/JCI200215021.

\section{Introduction}

Nitric oxide $\left(\mathrm{NO}^{*}\right)$ produced by the constitutive form of nitric oxide synthase plays a critical role in normal physiology by regulating vasomotor tone $(1,2)$. The larger amounts of $\mathrm{NO}^{\bullet}$ produced by the inducible isoform of the enzyme contribute to the ability of inflammatory cells to kill microbial organisms and tumor cells. Under pathological conditions, however, reactive nitrogen species derived from $\mathrm{NO}^{\bullet}$ may injure normal tissue (3). The most widely studied mechanism involves the rapid reaction of $\mathrm{NO}^{\bullet}$ with superoxide $(4,5)$ to produce peroxynitrite $\left(\mathrm{ONOO}^{-}\right)$. In vitro, $\mathrm{ONOO}^{-}$yields potent hydroxylating and nitrating species. Immunohistochemical studies suggest that $\mathrm{ONOO}^{-}$contributes to a variety of pathological conditions, including atherosclerosis, acute respiratory distress syndrome, and ischemia/reperfusion injury $(3,5)$.

Evidence that $\mathrm{ONOO}^{-}$provides a mechanism for oxidative damage rests largely on the detection of 3-nitrotyrosine in inflamed tissue $(3,5)$. However, immunohistochemical approaches are only semiquantitative. Moreover, cross-reacting but structurally distinct molecules may confound immunodetection. Many investigators have noted that artifact formation complicates analysis of oxidation products, and this has been a particular problem with 3-nitrotyrosine (6-10). It is also unclear whether $\mathrm{NO}^{\bullet}$ and superoxide produced at physiologically plausible rates will nitrate tyrosine efficiently in vitro (11-13), leaving open the possibility that 3-nitrotyrosine has a different origin in vivo.

$\mathrm{NO}{ }^{-}$can also autoxidize to nitrite $\left(\mathrm{NO}_{2}{ }^{-}\right)$and nitrate $\left(\mathrm{NO}_{3}{ }^{-}\right)$(14). Plasma levels of $\mathrm{NO}_{2}^{-}$, which range up to $4 \mu \mathrm{M}$ in healthy humans, increase markedly during acute and chronic inflammation (14). Because $\mathrm{NO}_{2}$ is a substrate for myeloperoxidase, a heme enzyme secreted by activated phagocytes, it might also be used for tyrosine nitration in vivo (15). Indeed, myeloperoxidase uses hydrogen peroxide $\left(\mathrm{H}_{2} \mathrm{O}_{2}\right)$ and $\mathrm{NO}_{2}{ }^{-}$to generate reactive nitrogen species that nitrate tyrosyl residues in vitro (16-18). These reactions might be physiologically relevant because human neutrophils 
can use the myeloperoxidase- $\mathrm{H}_{2} \mathrm{O}_{2}-\mathrm{NO}_{2}{ }^{-}$system to chlorinate and nitrate tyrosine analogues (17).

Despite intense interest in the role of reactive nitrogen species in host defense mechanisms and oxidative tissue injury, the in vivo pathways that promote nitration remain poorly understood $(1,2)$. The difficulty of quantifying nitrated tyrosine in biological samples has contributed to the lack of progress (6-10). In the current study, we use two clinically relevant models of sepsis and gas chromatography/mass spectrometry (GC/MS) to determine whether myeloperoxidase generates 3-nitrotyrosine in vivo (19). Mass spectrometry has the major advantage of being a quantitative method that permits the use of isotopomers for monitoring any analyte that forms ex vivo during sample work-up and analysis. Our experiments using this method provide strong evidence that myeloperoxidase generates nitrating oxidants in vivo, possibly by a pathway involving $\mathrm{NO}_{2}^{-}$.

\section{Methods}

General procedures. Myeloperoxidase was purified from HL60 cells $(20,21)$. Total $\mathrm{NO}_{2}{ }^{-}$and $\mathrm{NO}_{3}{ }^{-}$was quantified in peritoneal fluid using the Griess reagent (Cayman Chemical, Ann Arbor, Michigan, USA).

Animals. The Animal Studies Committee of Washington University School of Medicine in St. Louis approved all animal studies. Mice were maintained under pathogen-free conditions on a 12-hour light/dark schedule. Myeloperoxidase-deficient mice were generated in a 129/SvJ background; they were backcrossed at least four generations into the C57BL/6J background (The Jackson Laboratory, Bar Harbor, Maine, USA) prior to use (22). Experiments were performed with agematched (8-16 weeks) and sex-matched C57BL/6J mice.

Reaction conditions. Reactions were carried out for 60 minutes at $37^{\circ} \mathrm{C}$ in Chelex-treated (Bio-Rad, Hercules, California, USA) buffer A ( $100 \mathrm{mM} \mathrm{NaCl}, 50 \mathrm{mM}$ sodium phosphate, $100 \mu \mathrm{M}$ diethylenetriaminepentaacetic acid, pH 7.4) supplemented with $0.5 \mathrm{mM} \mathrm{N}$-acetyl-Ltyrosine. Reactions were initiated by adding $\mathrm{H}_{2} \mathrm{O}_{2}$ or $\mathrm{HOCl}$ and terminated with $0.1 \mathrm{mM}$ methionine and $200 \mathrm{nM}$ catalase.

Reverse-phase HPLC analysis. Analyses were performed using a flow rate of $1 \mathrm{ml} / \mathrm{min}$ and an Ultrasphere ODS reverse-phase column $(4.6 \mathrm{~mm} \times 25 \mathrm{~cm}$; $5 \mu \mathrm{m}$ resin; Beckman Instruments Inc., Fullerton, California, USA) as described $(10,23)$.

Bacterial killing. The bactericidal activity of myeloperoxidase was quantified as described (24). Briefly, Klebsiella pneumoniae were incubated alone or with $5 \mathrm{nM}$ enzyme, $5 \mathrm{nM} \mathrm{H}_{2} \mathrm{O}_{2}$, in $0.5 \mathrm{mM} \mathrm{NaOAc}$ buffer ( $\mathrm{pH} 5.0$ or $\mathrm{pH}$ 7.0) for 1 hour at $37^{\circ} \mathrm{C}$ with $0.1 \mathrm{mM}$ or $10 \mathrm{mM}$ $\mathrm{NaNO}_{2}$ and/or $100 \mathrm{mM} \mathrm{Cl}^{-}$. Serial dilutions were immediately spread on agar plates, and the CFUs were determined after overnight incubation at $37^{\circ} \mathrm{C}$.

Immunostaining of mouse neutrophils. Mouse neutrophils were elicited by intraperitoneal injection of $1 \mathrm{ml}$ of sterile $15 \%$ glycogen in PBS (pH 7.4). Four hours after injection, the cells were harvested by intraperitoneal lavage, contaminating red blood cells were lysed, and the neutrophils were washed three times with PBS ( $\mathrm{pH}$ 7.4) (24). Neutrophils were incubated with $K$. pneumoniae (24) in the presence or absence of $100 \mu \mathrm{M} \mathrm{NO}_{2}{ }^{-}$for 1 hour at $37^{\circ} \mathrm{C}$. Neutrophils were then washed three times with PBS, trypsinized, and cytospun onto slides. Cells were immunostained for nitrotyrosine using a rabbit polyclonal anti-nitrotyrosine antibody (Upstate Inc., Lake Placid, New York, USA) and a biotinylated goat anti-rabbit IgG secondary antibody according to the manufacturer (Vector Laboratories Inc., Burlingame, California, USA). Cells were immunostained for inducible nitric oxide synthase using a goat monoclonal anti-inducible nitric oxide synthase antibody (Santa Cruz Biotechnology Inc., Santa Cruz, California, USA) followed by a biotinylated rabbit anti-goat IgG antibody as described by the manufacturer (Vector Laboratories Inc.).

Sepsis models. Cecal ligation and puncture (CLP) was performed as described (23). Mice were injected intraperitoneally with $4 \times 10^{8} \mathrm{~K}$. pneumoniae. The peritoneum was lavaged 16 hours after injection with $10 \mathrm{ml}$ of PBS. Lavage fluid was stored at $-80^{\circ} \mathrm{C}$ until analysis.

Cell analysis. Cells were placed onto slides by centrifugation and stained with a modified Wright's stain (Dimscio and Associates, Manchester, Missouri, USA). Cell counts were performed by the Department of Comparative Medicine at Washington University School of Medicine.

Western blotting, immunoprecipitation, and protein identification. K. pneumoniae $\left(10^{8} / \mathrm{ml}\right)$ were incubated with $5 \mathrm{nM}$ myeloperoxidase, $100 \mu \mathrm{M} \mathrm{H}_{2} \mathrm{O}_{2}$, and $100 \mu \mathrm{M}$ or $500 \mu \mathrm{M}$ $\mathrm{NO}_{2}{ }^{-}$for 1 hour at $37^{\circ} \mathrm{C}$. Bacteria were pelleted by centrifugation and incubated with $4 \mathrm{mg} / \mathrm{ml}$ lysozyme, 50 $\mathrm{mM}$ glucose, $10 \mathrm{mM}$ EDTA, and $25 \mathrm{mM}$ Tris ( $\mathrm{pH}$ 8) for 5 minutes. The pellet was incubated with lysis buffer (150 mM NaCl, $1 \%$ NP-40, 0.1\% SDS, 50 mM Tris, pH 8) on ice for 30 minutes and centrifuged, and soluble proteins were subjected to SDS-PAGE. The separated proteins were transferred to a nitrocellulose membrane (preincubated with 5\% milk and 0.05\% Tween-20 in PBS) and probed with a rabbit polyclonal anti-nitrotyrosine antibody (Upstate Inc.) followed by a goat anti-rabbit Ig antibody (Santa Cruz Biotechnology Inc.) conjugated to horseradish peroxidase. Immunoreactive proteins were visualized using West Pico chemiluminescent substrate (Pierce Chemical Co., Rockford, Illinois, USA). Proteins were immunoprecipitated with mouse monoclonal antinitrotyrosine antibody coupled to agarose beads (Upstate Inc.), eluted with $4 \times$ Novex loading buffer (Invitrogen Corp., San Diego, California, USA), and subjected to SDS-PAGE. Protein bands were stained, excised from the gel, digested in situ with trypsin, and subjected to liquid chromatography-quadrupole time-of-flight mass spectrometry (25).

$G C / M S$ analysis. Samples were prepared and analyzed in the negative ion electron capture mode as described previously $(10,23)$. Amino acids were isolated from peritoneal fluid by solid-phase extraction following the addition of internal standards (L-3-nitro $\left[{ }^{13} \mathrm{C}_{6}\right]$ tyrosine, $\mathrm{L}-\left[{ }^{13} \mathrm{C}_{6}\right]$ tyrosine, $\mathrm{L}-\left[{ }^{13} \mathrm{C}_{9},{ }^{15} \mathrm{~N}\right]$ tyrosine). 3-Nitrotyrosine 
was derivatized and quantified using the ion at massto-charge ratio $(m / z) 518$ ([M-O-t-butyl-dimethylsilyl $\left.]^{-}\right)$ and the ion derived from the isotopically labeled $\left[{ }^{13} \mathrm{C}_{6}\right]$ internal standard $(\mathrm{m} / z$ 524). Potential artifact formation during sample work-up was monitored as the appearance of ion current at $\mathrm{m} / z 528$ derived from $\mathrm{L}-\left[{ }^{13} \mathrm{C}_{9},{ }^{15} \mathrm{~N}\right]$ tyrosine. 3-Nitrotyrosine measurements were corrected for the minimal quantities of product that sometimes formed during sample preparation. L-tyrosine was quantified using the ion at $\mathrm{m} / \mathrm{z} 407$ ([M-COO-t-butyl-dimethylsilyl] $]^{-}$) and the ion derived from $\mathrm{L}-\left[{ }^{13} \mathrm{C}_{9},{ }^{15} \mathrm{~N}\right]$ tyrosine at $\mathrm{m} / z 416$.

Statistical analysis. The strength of the statistical differences between pairs of groups was evaluated using the Student's $t$ test. Significance was accepted at $P<0.05$.

\section{Results}

Myeloperoxidase generates $\mathrm{N}$-acetyl-3-nitrotyrosine in vitro under physiologically relevant conditions. Previous studies have used the tyrosine analogue 4-hydroxyphenylacetic acid to investigate the production of reactive nitrogen species by myeloperoxidase in vitro $(17,18)$. To confirm that myeloperoxidase can nitrate tyrosine, we incubated the enzyme $(5 \mathrm{nM})$ with $\mathrm{NO}_{2}{ }^{-}(100 \mu \mathrm{M}), N$-acetyl-Ltyrosine $(0.5 \mathrm{mM}), \mathrm{H}_{2} \mathrm{O}_{2}(50 \mu \mathrm{M})$, and plasma concentrations of chloride ion $\left(\mathrm{Cl}^{-} ; 100 \mathrm{mM}\right)$ in phosphate buffer at neutral $\mathrm{pH}$. $\mathrm{N}$-acetyl-L-tyrosine was used instead of L-tyrosine itself to prevent the production of chloramines and $p$-hydroxyphenylacetaldehyde (26).

Reverse-phase HPLC analysis of the reaction mixture revealed three peaks of new material (peaks I-III, Figure 1a). Peak III contained the only product whose formation required the complete system (Figure 1a). The retention time and absorption spectrum of that product were identical to those of authentic $\mathrm{N}$-acetyl-3-nitrotyrosine (Figure 1a, inset). In contrast, generation of peaks I and II required myeloperoxidase and $\mathrm{H}_{2} \mathrm{O}_{2}$ but not $\mathrm{NO}_{2}{ }^{-}$. Tandem mass spectrometric analysis in the negative ion mode (27) demonstrated spectra that were consistent with $N$-acetyl-o, $o^{\prime}$-dityrosine (peak I, data not shown), $N$ acetyl-3-chlorotyrosine (peak II, data not shown), and $N$ acetyl-3-nitrotyrosine (peak III, Figure 1b). The identity of peak III as $N$-acetyl-3-nitrotyrosine was confirmed with high-resolution proton nuclear magnetic resonance spectroscopy (Figure 1c). Significant features included loss of the $\mathrm{C}-3$ proton resonance, a downfield shift in the $\mathrm{C}-2$ proton, and conversion of the $\mathrm{C}-2$ proton resonance from a doublet to a singlet.

Formation of $\mathrm{N}$-acetyl-3-nitrotyrosine required $\mathrm{NO}_{2}{ }^{-}$, $\mathrm{N}$-acetyl-L-tyrosine, $\mathrm{H}_{2} \mathrm{O}_{2}$, and myeloperoxidase. The reaction depended linearly on $\mathrm{NO}_{2}{ }^{-}$concentration over a physiologic range $(1-100 \mu \mathrm{M})$ and was complete in less than 10 minutes. It was inhibited by about $20 \%$ by plasma concentrations of $\mathrm{Cl}^{-}$and was also inhibited by the peroxide scavenger catalase and the heme poison sodium azide. These results indicate that myeloperoxidase nitrates $\mathrm{N}$-acetyl-L-tyrosine by a reaction that requires active enzyme, $\mathrm{NO}_{2}^{-}$, and $\mathrm{H}_{2} \mathrm{O}_{2}$, and that $\mathrm{N}$-acetyl-3-nitrotyrosine is the major stable product.
Myeloperoxidase generates $\mathrm{N}$-acetyl-3-nitrotyrosine by directly oxidizing $\mathrm{NO}_{2}{ }^{-}$. It has been proposed that myeloperoxidase uses two distinct pathways to generate reactive nitrogen species $(16-18,28,29)$. In the first pathway, the enzyme generates $\mathrm{HOCl}$, using $\mathrm{H}_{2} \mathrm{O}_{2}$ and $\mathrm{Cl}^{-}$(Equation 1 below) (30-32). The $\mathrm{HOCl}$ then reacts with $\mathrm{NO}_{2}{ }^{-}$to form nitryl chloride, a nitrating species (Equation 2). In the second pathway, myeloperoxidase uses a one-electron reaction to directly oxidize $\mathrm{NO}_{2}{ }^{-}$to nitrogen dioxide radical, $\mathrm{NO}_{2}{ }^{\bullet}$ (Equation 3 ). $\mathrm{NO}_{2}{ }^{\bullet}$ then might directly oxidize tyrosine, or it might react with the tyrosyl radical that myeloperoxidase also generates $(28,33)$.

\section{Equation 1}

$$
\mathrm{Cl}^{-}+\mathrm{H}_{2} \mathrm{O}_{2}+\mathrm{H}^{+} \rightarrow \mathrm{HOCl}+\mathrm{H}_{2} \mathrm{O}
$$

\section{Equation 2}

$$
\mathrm{HOCl}+\mathrm{NO}_{2}^{-} \rightarrow \mathrm{NO}_{2} \mathrm{Cl}+\mathrm{HO}^{-}
$$

\section{Equation 3}

$$
\mathrm{NO}_{2}^{-}+\text {compound I }+\mathrm{H}^{+} \rightarrow \mathrm{NO}_{2}{ }^{-}+\mathrm{H}_{2} \mathrm{O}+\text { compound II }
$$

To distinguish between these two pathways, we first compared the effect of $\mathrm{pH}$ on the ability of either a mixture of reagent $\mathrm{HOCl}$ and $\mathrm{NO}_{2}{ }^{-}$or the myeloperoxidase$\mathrm{H}_{2} \mathrm{O}_{2}-\mathrm{NO}_{2}{ }^{-}-\mathrm{Cl}^{-}$system to generate $\mathrm{N}$-acetyl-3-nitrotyrosine. Interestingly, the $\mathrm{HOCl}-\mathrm{NO}_{2}{ }^{-}$system operated optimally at neutral $\mathrm{pH}$, whereas the enzymatic system had an acidic pH optimum (Figure 2, a and b). This difference suggests that myeloperoxidase might be able to nitrate $N$-acetyl-L-tyrosine by a mechanism not involving HOCl. Alternatively, myeloperoxidase might generate $\mathrm{HOCl}$ most efficiently under acidic conditions.

We next determined whether taurine (2-aminoethanesulfonic acid, a potent scavenger of $\mathrm{HOCl})(31,34)$,

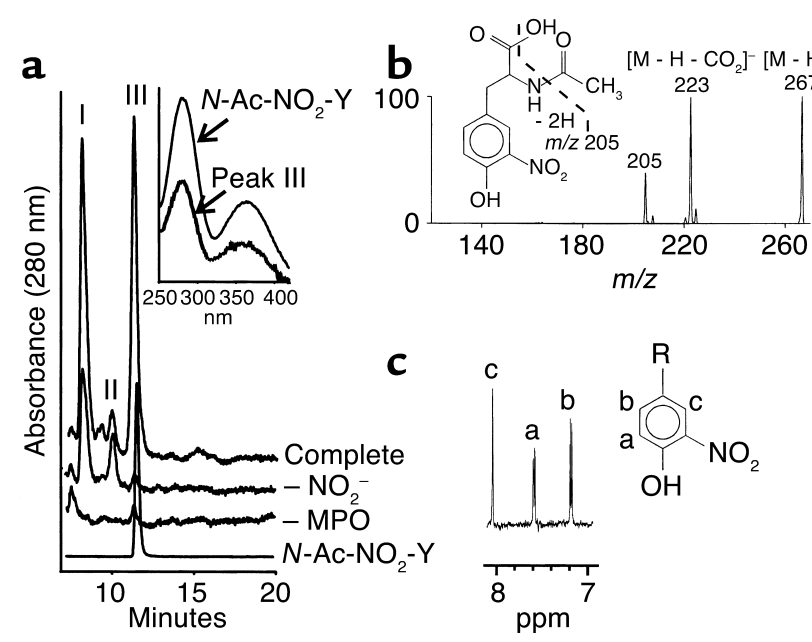

Figure 1

Analysis of $\mathrm{N}$-acetyl-L-tyrosine exposed to the myeloperoxidase- $\mathrm{NO}_{2}{ }^{-}-$ $\mathrm{Cl}^{-}-\mathrm{H}_{2} \mathrm{O}_{2}$ system. (a) HPLC analysis. Inset: Absorbance spectra of authentic $\mathrm{N}$-acetyl-L-3-nitrotyrosine ( $\mathrm{N}$-Ac-nitrotyrosine $\left[\mathrm{N}\right.$-Ac- $\left.\mathrm{NO}_{2}-\mathrm{Y}\right]$ ) and peak III. (b) Electrospray ionization tandem mass spectrometric analysis of peak III. (c) Aromatic region of a proton nuclear magnetic resonance spectrum of peak III. MPO, myeloperoxidase. 

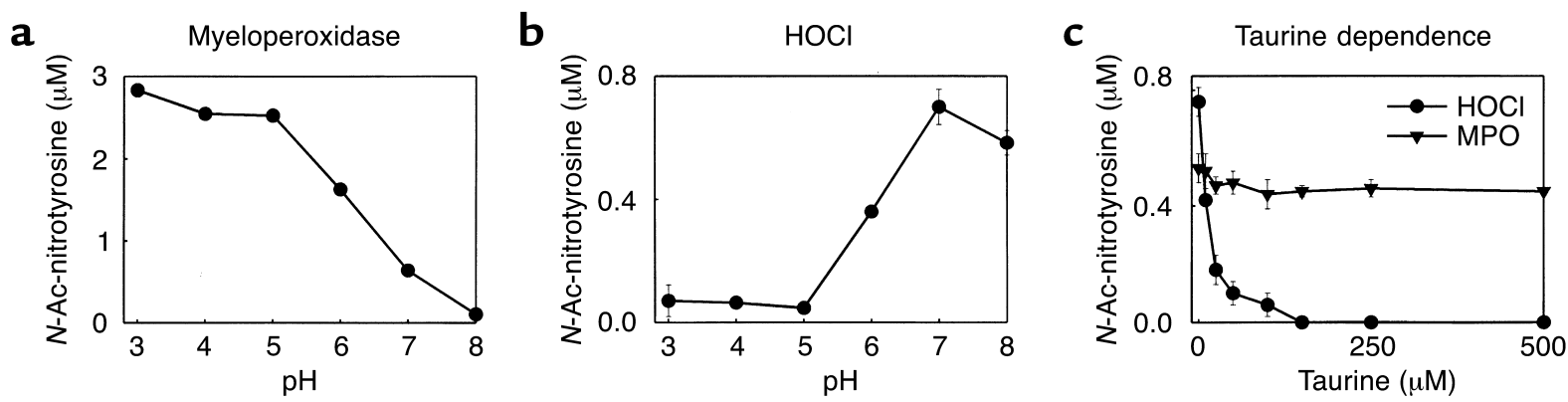

Figure 2

Reaction requirements for generation of $\mathrm{N}$-Ac-nitrotyrosine by $\mathrm{HOCl}$ and myeloperoxidase. (a and $\mathbf{b}) \mathrm{Effect}$ of $\mathrm{pH}$. (c) Effect of taurine. Results represent means \pm SEM of three independent experiments.

inhibited nitration by the $\mathrm{HOCl}-\mathrm{NO}_{2}{ }^{-}$mixture or the enzymatic system. Increasing concentrations of taurine progressively inhibited the conversion of $\mathrm{N}$-acetyl-Ltyrosine to $\mathrm{N}$-acetyl-3-nitrotyrosine by $\mathrm{HOCl}-\mathrm{NO}_{2}{ }^{-}$at neutral $\mathrm{pH}$ (Figure 2c). In marked contrast, taurine had no effect when myeloperoxidase nitrated $N$-acetyl-Ltyrosine. This result provides strong evidence that myeloperoxidase nitrates $N$-acetyl-L-tyrosine by a pathway not involving $\mathrm{HOCl}$. The pathway likely involves direct oxidation of $\mathrm{NO}_{2}^{-}$by compound I (Equation 3) and the reaction of $\mathrm{NO}_{2}{ }^{\bullet}$ with tyrosyl radical. It is noteworthy that myeloperoxidase preferentially oxidizes $\mathrm{NO}_{2}^{-}$under these conditions, despite the presence of 2000-fold greater levels of $\mathrm{Cl}^{-}$.

Myeloperoxidase uses $\mathrm{NO}_{2}{ }^{-}$and $\mathrm{H}_{2} \mathrm{O}_{2}$ to generate bactericidal oxidants. Because myeloperoxidase-deficient mice are more vulnerable to infection with the Gram-negative bacterium $K$. pneumoniae than are wild-type mice (our unpublished observation), we determined how $\mathrm{NO}_{2}{ }^{-}, \mathrm{Cl}^{-}$, and myeloperoxidase affect the killing of $K$. pneumoniae under neutral and acidic conditions (24). When the myeloperoxidase- $\mathrm{H}_{2} \mathrm{O}_{2}$ system in phosphate buffer at $\mathrm{pH} 7$ was supplemented with physiologically plausible concentrations of $\mathrm{NO}_{2}^{-}(0.1 \mathrm{mM})$ or $\mathrm{Cl}^{-}(100$ $\mathrm{mM}$ ), it killed about $70 \%$ of the bacteria in the reaction mixture. Similar results were observed when both $\mathrm{NO}_{2}{ }^{-}$ and $\mathrm{Cl}^{-}$were included. Peroxide alone failed to kill bacteria under these conditions.

Different results were observed at $\mathrm{pH}$ 5. The myeloperoxidase $-\mathrm{H}_{2} \mathrm{O}_{2}$ system supplemented with 100 $\mathrm{mM} \mathrm{Cl}^{-}$killed essentially all of the bacteria. In contrast, only $82 \%$ of the bacteria were killed when the reaction mixture included $\mathrm{NO}_{2}^{-}$at a level $(10 \mathrm{mM}) 100$-fold higher than that observed in plasma during inflammation. These observations indicate that the bactericidal activity of the myeloperoxidase- $\mathrm{H}_{2} \mathrm{O}_{2}-\mathrm{NO}_{2}{ }^{-}$system depends critically on the $\mathrm{pH}$ of the reaction mixture. Klebanoff reported that killing of Escherichia coli showed a similar $\mathrm{pH}$ dependency (15).

Myeloperoxidase nitrates bacterial proteins in vitro. To explore the potential contribution of protein nitration to the cytotoxic activity of the myeloperoxidase $-\mathrm{H}_{2} \mathrm{O}_{2}-$ $\mathrm{NO}_{2}{ }^{-}$system, we used a polyclonal antibody to nitrotyrosine to search for bacterial proteins that become nitrated in vitro. After exposing K. pneumoniae to myeloperoxidase, $\mathrm{H}_{2} \mathrm{O}_{2}$, and $\mathrm{NO}_{2}^{-}$(Figure 3a), we observed multiple bands of immunoreactive material in bacterial proteins subjected to SDS-PAGE and Western blotting. A protein of about $65 \mathrm{kDa}$ was particularly prominent (Figure 3a). Protein nitration required both myeloperoxidase and $\mathrm{NO}_{2}^{-}$(Figure $3 \mathrm{a}$ ).

To identify the nitrated proteins, bacterial proteins were immunoprecipitated with a mouse monoclonal anti-nitrotyrosine antibody. When the isolated material was separated using SDS-PAGE, protein staining revealed four major bands (Figure $3 b$ ). Once again, a protein of about $65 \mathrm{kDa}$ was particularly prominent. When the isolated material was subjected to Western blot analysis with the polyclonal anti-nitrotyrosine antibody, the only immunoreactive band was again the approximately 65-kDa protein (data not shown). Tandem mass spectrometric analysis of trypsin digests of the isolated protein identified the sequence VLVNTKATLAAFR (Figure 3c), a peptidyl aspartic acid metalloendopeptidase of the bacterium Psendomonas fragi. This sequence is not present in any known K. pneumoniae protein, but the complete genomic sequence of this organism is not available. These observations raise the possibility that reactive nitrogen species generated by myeloperoxidase contribute to bacterial killing by oxidizing specific protein targets such as metalloproteinases.

Depriving neutrophils of myeloperoxidase impairs their ability to nitrate cytoplasmic proteins. To determine whether nitration of tyrosine by myeloperoxidase might be physiologically relevant, we isolated neutrophils from wildtype and myeloperoxidase-deficient mice. We then incubated the cells with $K$. pneumoniae, a major cause of sepsis in humans, in the presence $(100 \mu \mathrm{M})$ or absence of $\mathrm{NO}_{2}^{-}$. One hour after infection, the neutrophils were immunostained with an anti-3-nitrotyrosine antibody. In the presence of $\mathrm{NO}_{2}^{-}$, the wild-type cells showed distinct cytoplasmic immunostaining (Figure 4a). A similar pattern of immunoreactivity was observed in the absence of $\mathrm{NO}_{2}{ }^{-}$(Figure $4 \mathrm{~b}$ ), but the immunostaining was less intense. In contrast, no immunostaining was observed in the cells that lacked functional myeloperoxidase in the presence (Figure 4c) or absence of $\mathrm{NO}_{2}$ (data not shown). Omitting the primary antibody or 
preincubating the 3-nitrotyrosine antibody with $10 \mathrm{mM}$ of 3-nitrotyrosine also prevented immunostaining of wild-type cells (data not shown). Because we observed immunoreactivity for 3-nitrotyrosine in the absence of $\mathrm{NO}_{2}^{-}$, we hypothesized that mouse neutrophils generate $\mathrm{NO}^{\bullet}$ after they are activated by $K$. pneumoniae (24, 35 ). Indeed, both wild-type and myeloperoxidase-deficient cells immunostained intensely for the inducible form of nitric oxide synthase (Figure 4, d-f). These results suggest that mouse neutrophils use myeloperoxidase to nitrate cytoplasmic proteins.

Free 3-nitrotyrosine is detectable in peritoneal fluid isolated from septic mice. To determine whether tyrosine is nitrated in vivo during inflammation, peritoneal fluid from septic mice was analyzed by isotope dilution GC/MS. We were aware that ex vivo formation of 3-nitrotyrosine can be a major problem during analysis of biological materials $(6,7,9,10)$. Indeed, some studies have suggested that virtually all of the 3-nitrotyrosine detected in plasma and tissue is generated artifactually $(6,7,9)$. To circumvent this problem, we used a method that avoids strongly acidic conditions during sample preparation and amino acid derivatization $(7,10,23)$. To confirm that any 3 -nitrotyrosine detected in inflammatory fluid was endogenous rather than artifactual, an isotope-labeled tyrosine (L- $\left[{ }^{13} \mathrm{C}_{9},{ }^{15} \mathrm{~N}\right]$ tyrosine) was routinely added to each sample before analysis. We reasoned that any procedure that converted endogenous tyrosine to 3-nitrotyrosine would also convert $\mathrm{L}-\left[{ }^{13} \mathrm{C}_{9},{ }^{15} \mathrm{~N}\right]$ tyrosine to 3 -nitro $\left[{ }^{13} \mathrm{C}_{9},{ }^{15} \mathrm{~N}\right]$ tyrosine. The latter would be detectable by GC/MS because its $m / z$ differs from those of 3-nitrotyrosine and the internal standard. Thus, its appearance would indicate that artifactual oxidation had taken place.

To determine whether L-tyrosine is nitrated during sepsis, the peritonea of wild-type mice were infected with $K$. pneumoniae. Sixteen hours later, the peritoneum was lavaged to obtain fluid containing white blood cells, bacteria, and inflammatory exudate. This lavage fluid was immediately frozen and stored at $-80^{\circ} \mathrm{C}$. For analysis, the fluid was thawed and centrifuged, and the supernatant was harvested. Less than $3 \%$ of the free tyrosine in the lavage fluid remained in the cellular pellet, demonstrating that free tyrosine from both the cellular and extracellular components of peritoneal lavage fluid was recovered quantitatively by this procedure. Isotope dilution GC/MS was used to quantify free 3 -nitrotyrosine in the supernatant $(7,10,23)$. The derivatized material contained a compound that exhibited the major ion and retention time identical to those of authentic 3-nitrotyrosine. Selected ion monitoring showed that the ion derived from the amino acid (Figure $5 a)$ co-eluted with the ion derived from ${ }^{13} \mathrm{C}$-labeled internal standard (3-nitro $\left[{ }^{13} \mathrm{C}_{6}\right]$ tyrosine; Figure $5 \mathrm{~b}$ ). In contrast, there was little evidence for 3-nitrotyrosine formation during sample work-up and analysis $\left(3\right.$-nitro $\left[{ }^{13} \mathrm{C}_{9}\right.$, ${ }^{15} \mathrm{~N}$ ]tyrosine; Figure $5 \mathrm{c}$ ). These observations indicate that free 3-nitrotyrosine is detectable in peritoneal lavage fluid from mice infected with $K$. pneumoniae and that the compound is not generated ex vivo during analysis.
Myeloperoxidase generates 3-nitrotyrosine during acute inflammation. To determine whether myeloperoxidase could have generated the 3 -nitrotyrosine observed in peritoneal fluid, we investigated 3-nitrotyrosine formation in two models of acute inflammation characterized by an intense neutrophil response $(23,24)$. The first model (described above) employed the intraperitoneal injection of $K$. pneumoniae. Neutrophils were the predominant cells in lavage fluid from both the wild-type animals $(n=3 ; 97 \% \pm 1 \%$ neutrophils, $1 \% \pm 0 \%$ macrophages, $2 \% \pm 1 \%$ eosinophils)

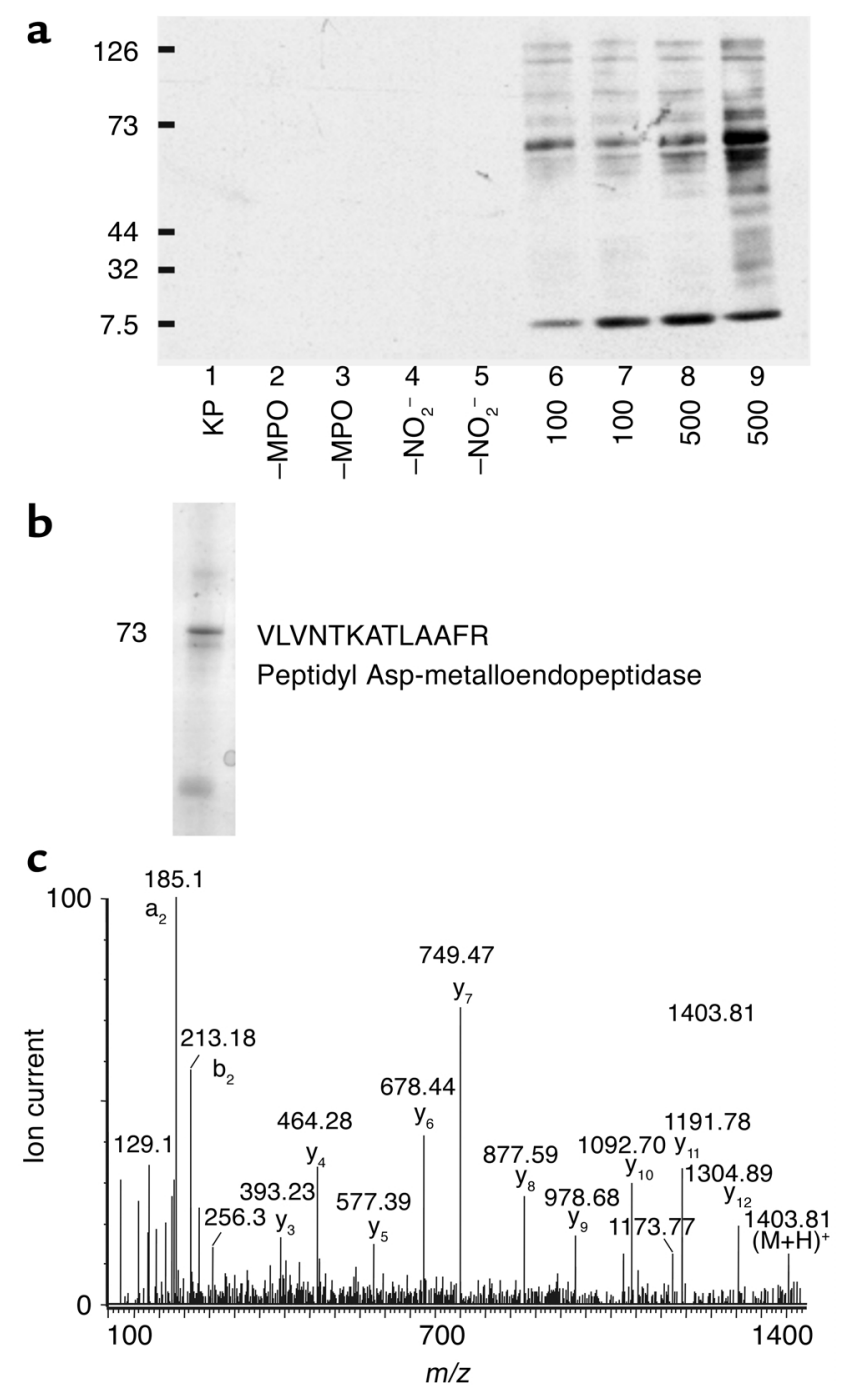

\section{Figure 3}

Western blot analysis and immunoprecipitation of $K$. pneumoniae proteins exposed to the myeloperoxidase- $\mathrm{H}_{2} \mathrm{O}_{2}-\mathrm{NO}_{2}{ }^{-}$system at neutral $\mathrm{PH}$. (a) Western blot analysis of nitrated proteins isolated from a reaction mixture containing $K$. pneumoniae (KP), myeloperoxidase, $\mathrm{H}_{2} \mathrm{O}_{2}$, and $\mathrm{NO}_{2}{ }^{-}(100$ or $500 \mu \mathrm{M})$. Proteins were probed with a rabbit polyclonal antibody to 3-nitrotyrosine. (b) Solubilized proteins from $K$. pneumoniae exposed to myeloperoxidase, $\mathrm{H}_{2} \mathrm{O}_{2}$, and $\mathrm{NO}_{2}$ were immunoprecipitated with a mouse $\mathrm{mAb}$ to 3-nitrotyrosine. Only the protein of about $65 \mathrm{kDa}$ was immunoreactive with a rabbit polyclonal antibody to 3-nitrotyrosine. (c) Tandem mass spectrometric analysis of a trypsin digest of the immunoreactive $65-\mathrm{kDa}$ protein. $(\mathrm{M}+\mathrm{H})^{+}$, molecularion. 


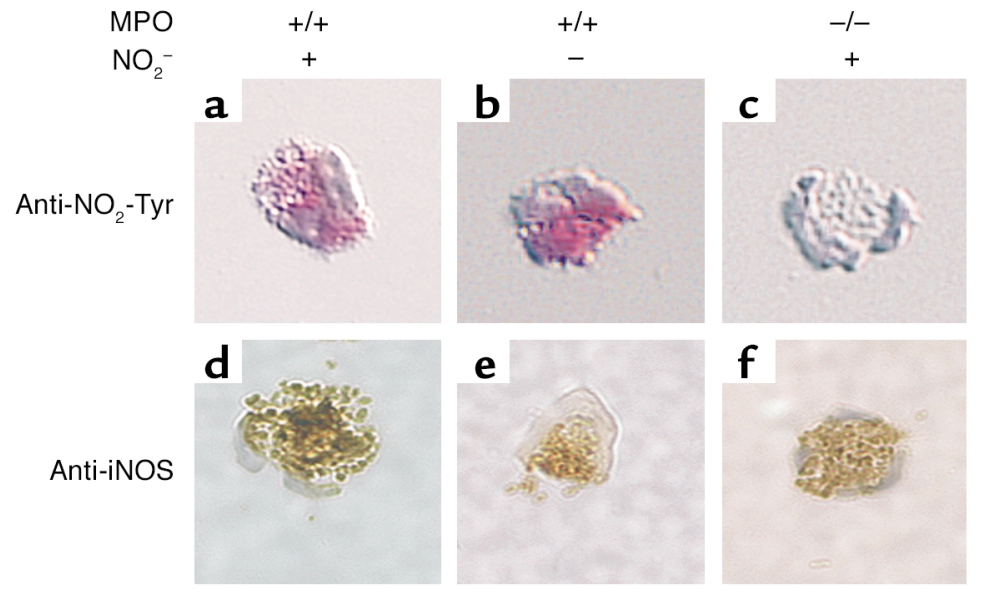

\section{Figure 4}

Immunohistochemical staining of wild-type and myeloperoxidase-deficient neutrophils for 3-nitrotyrosine (red immunostaining; $\mathbf{a}-\mathbf{c}$ ) or inducible nitric oxide synthase (iNOS) (brown immunostaining; d-f). Cells were incubated with $K$. pneumoniae in the presence $(\mathbf{a}, \mathbf{c}, \mathbf{d}$, and f) or absence ( $\mathbf{b}$ and $\mathbf{e}$ ) of $\mathrm{NO}_{2}^{-}$and then subjected to immunostaining.

increases markedly in the normal mouse peritoneum during sepsis, that myeloperoxidase-deficient mice lack immunoreactive myeloperoxidase, and that both the wildtype mice and the genetically altered mice make eosinophil peroxidase.

Previous studies have demonstrated that neutrophils employ myeloperoxidase to gen-

and the myeloperoxidase-deficient animals $(n=3$; $96 \% \pm 1 \%$ neutrophils, $2 \% \pm 1 \%$ macrophages, $3 \% \pm 2 \%$ eosinophils). Occasional red blood cells and abundant intracellular and extracellular microorganisms were also apparent. Importantly, the cellular response to sepsis of the myeloperoxidase-deficient animals was comparable to that of the wild-type animals.

The second model was a clinically relevant mouse model that creates sepsis through cecal ligation and puncture (CLP), which allows intestinal bacteria to leak into the peritoneum. Neutrophils predominate in the lavage fluid, and myeloperoxidase deficiency does not affect their abundance (23). However, the peritoneal inflammatory fluid contains more red blood cells and cellular debris than does lavage fluid from mice infected with $K$. pneumoniae.

Peritoneal lavage fluid from wild-type mice subjected to either CLP or infection with $K$. pneumonia had markedly higher levels of immunoreactive myeloperoxidase than did peritoneal lavage fluid from control mice. In contrast, peritoneal fluid isolated from the septic myeloperoxidase-deficient mice contained no immunoreactive protein. We have previously shown that myeloperoxidase-deficient mice produce active eosinophil peroxidase (23). These results indicate that the number of myeloperoxidase-containing cells erate chlorinating intermediates in vivo (23). Consistent with these observations, we detected a marked increase in levels of 3-chlorotyrosine in both models of inflammation (Figure 6a). This increase was almost completely abrogated in myeloperoxidase-deficient mice. To determine whether myeloperoxidase similarly generates nitrating species in vivo, 3-nitrotyrosine levels were quantified by isotope dilution GC/MS (Figure 6b). In this analysis, we observed a striking difference between the two models. Peritoneal lavage fluid from wild-type mice and myeloperoxidase-deficient mice subjected to CLP contained similar levels of 3-nitrotyrosine (Figure 6b). However, the level of 3-nitrotyrosine in lavage fluid from wild-type mice infected with $K$. pneumoniae was 2.5 -fold higher than the level in fluid from myeloperoxidase-deficient animals (Figure 6b) $(P<0.01)$. The latter was similar to the levels observed after wild-type mice and myeloperoxidase-deficient mice were subjected to CLP. Collectively, these results indicate that a myeloperoxidase-dependent pathway nitrates tyrosine during the acute inflammation that follows K. pneumoniae infection but not during the tyrosine nitration that occurs after CLP.

K. pneumoniae infection markedly increases $\mathrm{NO}_{2}{ }^{-}$and $\mathrm{NO}_{3}{ }^{-}$levels. Myeloperoxidase generates reactive nitrogen species in vitro by a reaction pathway that
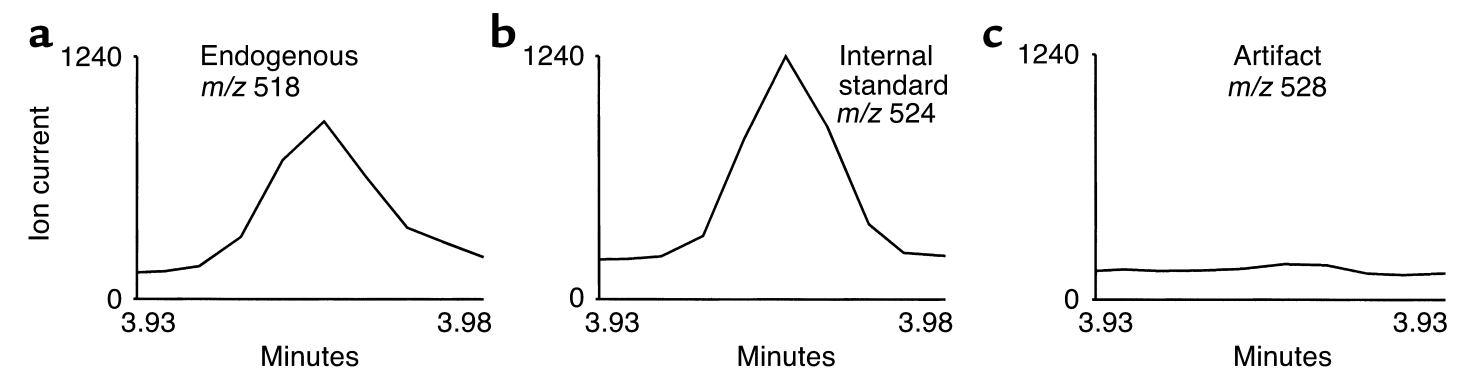

Figure 5

Detection of free 3-nitrotyrosine in peritoneal inflammatory exudate of a wild-type mouse infected with $K$. pneumoniae. Amino acids were isolated from peritoneal fluid by solid-phase chromatography, converted to their heptafluobutyryl $t$-butyl-dimethylsilyl derivatives, and subjected to GC/MS analysis. (a) Endogenous ( $\mathrm{m} / \mathrm{z} 518)$, (b) isotope-labeled ( $\mathrm{m} / \mathrm{z} 524)$, and (c) artifactual ( $\mathrm{m} / \mathrm{z}$ 528) 3-nitrotyrosine was monitored simultaneously using selected ion monitoring in the negative ion electron capture mode. 

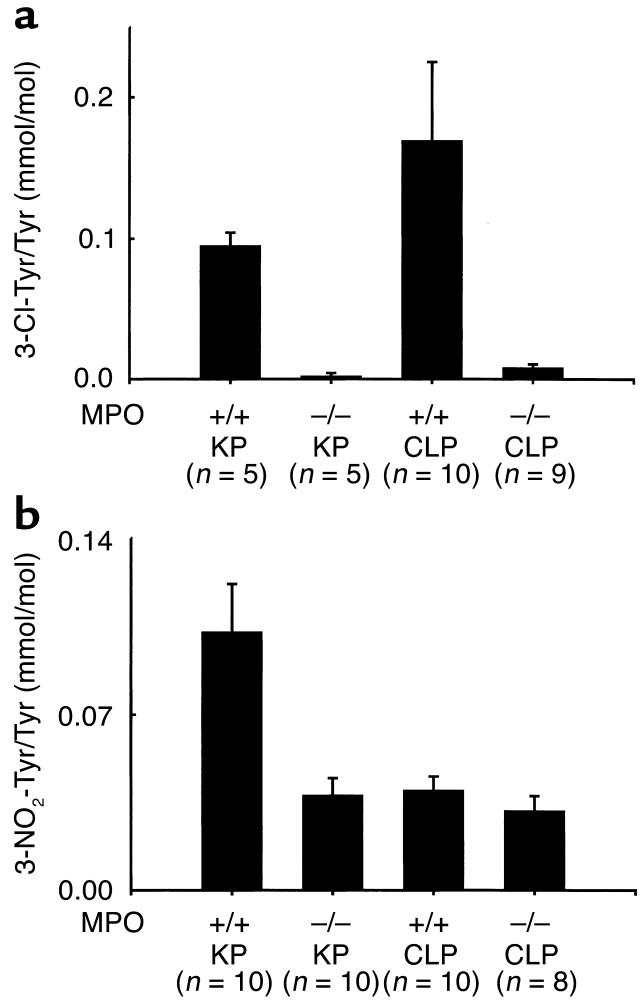

Figure 6

Quantification of (a) free 3-chlorotyrosine and (b) free 3-nitrotyrosine in peritoneal fluid isolated from wild-type and myeloperoxidase-deficient mice subjected to either CLP or infection with $K$. pneumoniae. 3-Chlorotyrosine (3-Cl-Tyr) and 3-nitrotyrosine (3- $\left.\mathrm{NO}_{2}-\mathrm{Tyr}\right)$ were quantified by isotope dilution GC/MS with selected ion monitoring in negative ion electron capture mode. KP, infection with $K$. pneumoniae.

requires $\mathrm{NO}_{2}^{-}$. To determine whether $\mathrm{NO}_{2}^{-}$is available during inflammation, levels of $\mathrm{NO}_{2}{ }^{-}$and $\mathrm{NO}_{3}{ }^{-}$were quantified in peritoneal lavage fluid from mice subjected to the two different models of inflammation. Levels of total $\mathrm{NO}_{2}{ }^{-}$and $\mathrm{NO}_{3}{ }^{-}$were 20 -fold higher in mice injected with $K$. pneumoniae than in mice subjected to CLP (Figure 7). Levels of total $\mathrm{NO}_{2}{ }^{-}$and $\mathrm{NO}_{3}{ }^{-}$were similar in sham-operated mice and mice subjected to CLP (data not shown). There was no significant difference in the levels of total $\mathrm{NO}_{2}{ }^{-}$and $\mathrm{NO}_{3}{ }^{-}$between the wild-type mice and myeloperoxidase-deficient mice in either model. These observations strongly suggest that myeloperoxidase requires elevated levels of $\mathrm{NO}^{*}$ or products derived from $\mathrm{NO}^{*}$ to produce reactive nitrogen species in vivo.

\section{Discussion}

More than 40 years ago, Chance demonstrated that $\mathrm{NO}_{2}{ }^{-}$can serve as a substrate for peroxidases (36). Moreover, nitrating oxidants are implicated in host defense mechanisms and the pathogenesis of many diseases (1, $3,5)$. Recent studies show that myeloperoxidase and other peroxidases use $\mathrm{H}_{2} \mathrm{O}_{2}$ and $\mathrm{NO}_{2}^{-}$to nitrate tyrosine in vitro $(15-18,37)$, leading to the proposal that peroxidases contribute to the generation of reactive nitrogen species and inflammation in vivo. However, it is not yet established whether peroxidases are physiologically relevant sources of nitrating oxidants.

To determine whether myeloperoxidase nitrates tyrosine in vivo, we used isotope dilution GC/MS to quantify 3-nitrotyrosine levels in lavage fluid from septic mice, using two models of acute peritoneal inflammation. We found that, after infection with $K$. pneumoniae, wild-type mice had markedly higher levels of free 3-nitrotyrosine than did myeloperoxidase-deficient mice. After CLP, however, wild-type and myeloperoxidase-deficient mice had comparable levels of the nitrated amino acid. Although both models of intraabdominal inflammation were characterized by an intense neutrophil response and a marked increase in levels of 3-chlorotyrosine, a marker of myeloperoxidase action, they differed in one important respect. Levels of total $\mathrm{NO}_{2}{ }^{-}$and $\mathrm{NO}_{3}{ }^{-}$ were 20 -fold higher in mice injected with $K$. pneumoniae than in mice subjected to CLP. These results indicate that myeloperoxidase generates oxidants that can nitrate tyrosine after mice are infected with $K$. pneumoniae. They also suggest that the enzyme generates these oxidants only under conditions associated with marked increases in $\mathrm{NO}_{2}{ }^{-}$and $\mathrm{NO}_{3}{ }^{-}$. Our observations strongly support the proposal that myeloperoxidase uses $\mathrm{NO}_{2}$ or other $\mathrm{NO}^{*}$-derived species to produce inflammatory nitrating oxidants in vivo.

3-Nitrotyrosine was detectable in myeloperoxidasedeficient mice, indicating that pathways independent of the enzyme contribute to 3-nitrotyrosine formation in vivo. Potential mechanisms include uptake of 3-nitrotyrosine from the gastrointestinal track (perhaps generated by the interaction of $\mathrm{NO}_{2}{ }^{-}$and tyrosine in the acidic milieu of the stomach) (38), reactive nitrogen species generated by other peroxidases such as eosinophil peroxidase (37), and $\mathrm{ONOO}^{-}$derived from the interaction of superoxide and $\mathrm{NO}^{\bullet}(4,5)$. It is interesting to note that myeloperoxidase-deficient mice injected with $K$. pneumoniae increased their levels of total $\mathrm{NO}_{2}{ }^{-}$and $\mathrm{NO}_{3}{ }^{-} 20$-fold but failed to demonstrate

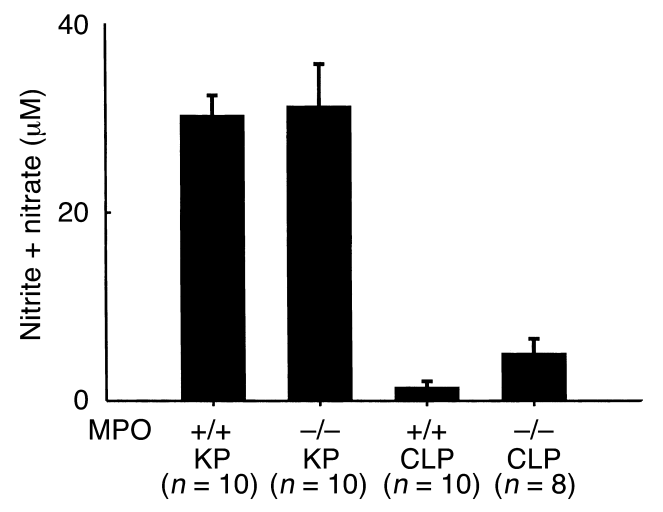

Figure 7

Quantification of $\mathrm{NO}_{2}{ }^{-}$and $\mathrm{NO}_{3}{ }^{-}$levels in peritoneal fluid isolated from wild-type and myeloperoxidase-deficient mice subjected to either CLP or infection with K. pneumoniae. Total $\mathrm{NO}_{2}{ }^{-}$and $\mathrm{NO}_{3}{ }^{-}$in peritoneal lavage fluid was quantified using the Griess reagent. 
any increase in 3-nitrotyrosine. These observations strongly suggest that all of the excess 3-nitrotyrosine generated in the K. pneumoniae model of inflammation is myeloperoxidase-dependent, even though infection with this bacterium markedly increases the production of $\mathrm{NO}^{\circ}$, which can be converted into $\mathrm{ONOO}^{-}$.

Myeloperoxidase is secreted both extracellularly and into the phagolysosome, suggesting that it might generate reactive nitrogen species in either environment. The immunochemical detection of 3-nitrotyrosine in bacteria ingested by cytokine-treated human neutrophils suggests that the enzyme might nitrate in the phagolysosome (35). However, studies using a fluorescent probe failed to demonstrate that reactive nitrogen species are generated in the phagolysosome of human neutrophils (39). Our immunohistochemical results suggest that mouse neutrophils can nitrate cytoplasmic proteins. The reaction appears optimal when physiologically relevant concentrations of $\mathrm{NO}_{2}{ }^{-}$are provided, but we observed a readily detectable level of nitration by wild-type mouse neutrophils even in the absence of $\mathrm{NO}_{2}{ }^{-}$. In contrast, myeloperoxidase-deficient mouse neutrophils were apparently unable to nitrate cytoplasmic proteins in the presence or absence of $\mathrm{NO}_{2}^{-}$, indicating that protein nitration in this system was completely dependent upon myeloperoxidase.

At least two factors might contribute to the discrepancy between the immunohistochemical and chemical studies. First, immunohistochemistry might be more sensitive than HPLC for detecting 3-nitrotyrosine. It is also possible that the antibodies used for the immunohistochemical studies react with a molecule that is structurally distinct from 3-nitrotyrosine. Second, mouse and human neutrophils might differ in their ability to execute nitration reactions intracellularly or in the phagolysosome (1). One particularly important factor might be the much higher levels of inducible nitric oxide synthase in mouse neutrophils than in human neutrophils (40-42). These observations suggest that the myeloperoxidase system of mouse neutrophils uses at least two pathways to generate reactive nitrogen species. One involves exogenous $\mathrm{NO}_{2}^{-}$and/or other species derived from $\mathrm{NO}^{\bullet}$, and the other involves products derived from inducible nitric oxide synthase in the neutrophil itself. Because human neutrophils contain very low levels of inducible nitric oxide synthase (40-42), they are unlikely to generate reactive nitrogen species intracellularly or in the phagolysosome (39). Instead, human neutrophils are likely to rely on $\mathrm{NO}_{2}$ - from other sources to generate nitrating oxidants in the extracellular environment. The inflammatory milieu provides all of the factors - numerous phagocytes and a high local concentration of $\mathrm{NO}^{\bullet}-$ necessary for the generation of nitrating oxidants by myeloperoxidase (1).

A key question is whether reactive nitrogen species generated by myeloperoxidase promote tissue damage. For example, enzymatically active myeloperoxidase is present in human atherosclerotic lesions, and 3-nitrotyrosine has been detected in LDL isolated from this tissue $(43,44)$. Reactive nitrogen species produced by myeloperoxidase peroxidize the lipid moieties of LDL in vitro, converting the lipoprotein to a form that is recognized by the macrophage scavenger receptor $(29,45)$. Unregulated uptake of such modified lipoprotein may play a role in cholesterol accumulation by macrophages, a critical early step in atherogenesis (45). The detection of elevated levels of 3-nitrotyrosine and 3-chlorotyrosine in LDL isolated from atherosclerotic lesions suggest that reactive intermediates derived from myeloperoxidase may indeed promote atherosclerotic vascular disease $(43,44,46)$.

Reactive nitrogen species produced by phagocytic white blood cells might also play a key role in host defense mechanisms by interacting with bacterial proteins, disabling them, and causing dysfunction of the bacterium (1). In a mouse model of Gram-negative pneumonia, products derived from nitric oxide synthase play a critical role in killing $K$. pneumoniae (47). We found that $\mathrm{NO}_{2}{ }^{-}$enables myeloperoxidase to kill $K$. pneumoniae efficiently at neutral $\mathrm{pH}$, and we have recently shown that neutrophils use myeloperoxidase to generate antimicrobial chlorinating and brominating intermediates in vivo (23), raising the possibility that reactive nitrogen species also promote bacterial killing. An important unresolved issue is the identity of the cellular machinery targeted for damage during oxidative bacterial killing. To approach this issue, we used immunoprecipitation coupled with mass spectrometry to identify bacterial proteins targeted for nitration by the myeloperoxidase- $\mathrm{H}_{2} \mathrm{O}_{2}-\mathrm{NO}_{2}{ }^{-}$system in vitro. Our results revealed one susceptible protein; its sequence showed similarities to a bacterial metalloproteinase. Interestingly, metalloproteinases produced by pathogenic microorganisms might be toxic to hosts (48). In future studies, it will be important to identify other bacterial targets for nitration, to investigate the physiologic function of the metalloproteinase-like protein that we identified, and to determine whether nitration of bacterial proteins by myeloperoxidase might impair the pathogenicity of $K$. pneumoniae.

In summary, our results show that myeloperoxidase secreted by neutrophils generates 3-nitrotyrosine during acute inflammation under conditions where extracellular levels of $\mathrm{NO}_{2}^{-}$and $\mathrm{NO}_{3}{ }^{-}$increase markedly. One mechanism might involve direct oxidation of $\mathrm{NO}_{2}^{-}$to $\mathrm{NO}_{2}{ }^{\circ}$. Because $\mathrm{NO}_{2}^{-}$enables myeloperoxidase to kill $K$. pneumoniae efficiently at neutral $\mathrm{pH}$, this system might represent a novel host defense mechanism. Moreover, elevated levels of 3-nitrotyrosine have been detected in many acute and chronic human inflammatory diseases. We have recently shown that neutrophils employ the myeloperoxidase system to chlorinate tyrosine residues in vivo (23). Levels of myeloperoxidase, 3 -nitrotyrosine, and 3-chlorotyrosine are elevated in human atherosclerotic tissue $(43,44,46)$. Therefore, reactive nitrogen species produced by myeloperoxidase might also play a role in inflammatory tissue injury and the pathogenesis of human disease. 


\section{Acknowledgments}

We thank William Parks (Washington University) for assistance with immunohistochemical studies. Mass spectrometry experiments were performed at the Washington University School of Medicine Mass Spectrometry Resource. This work was supported by grants from the NIH (AG-121191, AG-19309, HL-64344, DK-56341, and RR-00954) and the Washington University-Pharmacia Research Program. J.P. Gaut was supported by a Cardiovascular Training Grant at Washington University School of Medicine and a grant from the Glenn/American Federation of Aging Research.

1. Nathan, C., and Shiloh, M.U. 2000. Reactive oxygen and nitrogen intermediates in the relationship between mammalian hosts and microbial pathogens. Proc. Natl. Acad. Sci. USA. 97:8841-8848.

2. Moncada, S., and Higgs, A. 1993. The L-arginine-nitric oxide pathway. N. Engl. J. Med. 329:2002-2012.

3. Ischiropoulos, H. 1998. Biological tyrosine nitration: a pathophysiological function of nitric oxide and reactive oxygen species. Arch. Biochem. Biophys. 356:1-11.

4. Beckman, J.S., Beckman, T.W., Chen, J., Marshall, P.A., and Freeman, B.A. 1990. Apparent hydroxyl radical production by peroxynitrite: implications for endothelial injury from nitric oxide and superoxide. Proc. Natl. Acad. Sci. USA. 87:1620-1624.

5. Beckman, J.S. 1996. Oxidative damage and tyrosine nitration from peroxynitrite. Chem. Res. Toxicol. 9:836-844.

6. Yi, D., Ingelse, B., Duncan, M., and Smythe, G. 2000. Quantification of 3-nitrotyrosine in biological tissues and fluids: generating valid results by eliminating artifactual formation. J. Am. Soc. Mass Spectrom. 11:578-586.

7. Frost, M.T., Halliwell, B., and Moore, K.P. 2000. Analysis of free and protein-bound nitrotyrosine in human plasma by a gas chromatography/ mass spectrometry method that avoids nitration artifacts. Biochem. $J$. 345:453-458.

8. Halliwell, B., Zhao, K., and Whiteman, M. 1999. Nitric oxide and peroxynitrite. The ugly, uglier, and the not so good: a personal review of recent controversies. Free Radic. Res. 31:651-669.

9. Shigenaga, M.K., et al. 1997. Inflammation and NOx-induced nitration: assay for 3-nitrotyrosine by HPLC with electrochemical detection. Proc. Natl. Acad. Sci. USA. 94:3211-3216.

10. Gaut, J.P., Byun, J., Tran, H.D., and Heinecke, J.W. 2002. Artifact-free quantification of free 3-chlorotyrosine, 3-bromotyrosine, and 3-nitrotyrosine in human plasma by electron capture-negative chemical ionization gas chromatography mass spectrometry and liquid chromatography electrospray ionization tandem mass spectrometry. Anal. Biochem. 300:252-259.

11. Pfeiffer, S., Schmidt, K., and Mayer, B. 2000. Dityrosine formation outcompetes tyrosine nitration at low steady-state concentrations of peroxynitrite. J. Biol. Chem. 275:6346-6352.

12. Reiter, C.D., Teng, R.J., and Beckman, J.S. 2000. Superoxide reacts with nitric oxide to nitrate tyrosine at physiological $\mathrm{pH}$ via peroxynitrite. J. Biol. Chem. 275:32460-32466.

13. Pfeiffer, S., Lass, A., Schmidt, K., and Mayer, B. 2001. Protein tyrosine nitration in cytokine-activated murine macrophages. Involvement of a peroxidase/nitrite pathway rather than peroxynitrite. J. Biol. Chem. 276:34051-34058

14. Farrell, A.J., Blake, D.R., Palmer, R.M.J., and Moncada, S. 1992. Increased concentrations of nitrite in synovial fluid and serum samples suggest increased nitric oxide synthesis in rheumatic diseases. Ann. Rheum. Dis. 51:1219-1222.

15. Klebanoff, S. 1993. Reactive nitrogen intermediates and antimicrobial activity: role of nitrite. Free Radic. Biol. Med. 14:351-360.

16. Eiserich, J.P., Cross, C.E., Jones, A.D., Halliwell, B., and van der Vliet, A. 1996. Formation of nitrating and chlorinating species by reaction of nitrite with hypochlorous acid. J. Biol. Chem. 271:19199-19208.

17. Eiserich, J.P., et al. 1998. Formation of nitric oxide-derived inflammatory oxidants by myeloperoxidase in neutrophils. Nature. 391:393-397.

18. van der Vliet, A., Eiserich, J.P., Halliwell, B., and Cross, C.E. 1997. Formation of reactive nitrogen species during peroxidase-catalyzed oxidation of nitrite. J. Biol. Chem. 272:7617-7625.

19. Heinecke, J.W., et al. 1999. Detecting oxidative modification of biomolecules with isotope dilution mass spectrometry: sensitive and quantitative assays for oxidized amino acids in proteins and tissues. Methods Enzymol. 300:124-144.

20. Heinecke, J.W., Li, W., Daehnke, H.L., III, and Goldstein, J.A. 1993. Dityrosine, a specific marker of oxidation, is synthesized by the myeloperoxidase-hydrogen peroxide system of human neutrophils and macrophages. J. Biol. Chem. 268:4069-4077.
21. Hope, H.R., et al. 2000. Large-scale purification of myeloperoxidase from HL60 promyelocytic cells: characterization and comparison to human neutrophil myeloperoxidase. Protein Expr. Purif. 18:269-276.

22. Brennan, M.-L., et al. 2001. Increased athersclerosis in myeloperoxidasedeficient mice. J. Clin. Invest. 107:419-430.

23. Gaut, J.P., et al. 2001. Neutrophils employ the myeloperoxidase system to generate antimicrobial brominating and chlorinating oxidants during sepsis. Proc. Natl. Acad. Sci. USA. 98:11961-11966.

24. Belaaouaj, A., et al. 1998. Mice lacking neutrophil elastase reveal impaired host defense against gram negative bacterial sepsis. Nat. Med. 4:615-618.

25. Lauber, W.M., et al. 2001. Mass spectrometry compatibility of two-dimensional gel protein stains. Electrophoresis. 22:906-918.

26. Hazen, S.L., Hsu, F.F., and Heinecke, J.W. 1996. p-Hydroxyphenylacetaldehyde is the major product of $L$-tyrosine oxidation by activated human phagocytes. A chloride-dependent mechanism for the conversion of free amino acids into reactive aldehydes by myeloperoxidase. J. Biol. Chem. 271:1861-1867.

27. Byun, J., Henderson, J.P., Mueller, D.M., and Heinecke, J.W. 1999. 8Nitro-2'-deoxyguanosine, a specific marker of oxidation by reactive nitrogen species, is generated by the myeloperoxidase-hydrogen peroxide-nitrite system of activated human phagocytes. Biochemistry. 38:2590-2600.

28. van Dalen, C.J., Winterbourn, C.C., Senthilmohahn, R., and Kettle, A.J. 2000. Nitrite as a substrate and inhibitor of myeloperoxidase. J. Biol. Chem. 275:11638-11644.

29. Byun, J., Mueller, D.M., Fabjan, J.S., and Heinecke, J.W. 1999. Nitrogen dioxide radical generated by the myeloperoxidase-hydrogen peroxide-nitrite system promotes lipid peroxidation of low density lipoprotein. FEBS Letters. 455:243-246.

30. Harrison, J.E., and Schultz, J. 1976. Studies on the chlorinating activity of myeloperoxidase. J. Biol. Chem. 251:1371-1374.

31. Hampton, M., Kettle, A., and Winterbourn, C. 1998. Inside the neutrophil phagosome: oxidants, myeloperoxidase, and bacterial killing. Blood. 92:3007-3017.

32. Foote, C.S., Goyne, T.E., and Lehrer, R.I. 1981. Assessment of chlorination by human neutrophils. Nature. 301:715-716.

33. McCormick, M.L., et al. 1998. Electron paramagnetic resonance detection of free tyrosyl radical generated by myeloperoxidase, lactoperoxidase, and horseradish peroxidase. J. Biol. Chem. 273:32030-32037.

34. Henderson, J.P., et al. 2001. Production of brominating intermediates by myeloperoxidase: a transhalogenation pathway for generating mutagenic nucleobases during inflammation. J. Biol. Chem. 276:2867-2875.

35. Evans, T., et al. 1996. Cytokine-treated human neutrophils contain inducible nitric oxide synthase that produces nitration of ingested bacteria. Proc. Natl. Acad. Sci. USA. 93:9553-9558.

36. Chance, B. 1952. The kinetics of the complexes of peroxidase formed in the presence of chlorite or hypochlorite. Arch. Biochem. Biophys. 41:425-431.

37. Wu, W., Chen, Y., and Hazen, S.L. 1999. Eosinophil peroxidase nitrates protein tyrosyl residues. J. Biol. Chem. 274:25933-25944.

38. Ohshima, H., Friesen, M., Brouet, I., and Bartsch, H. 1990. Nitrotyrosine as a new marker for endogenous nitrosation and nitration of proteins. Food Chem. Toxicol. 28:647-652.

39. Jiang, Q., and Hurst, J.K. 1997. Relative chlorinating, nitrating, and oxidizing capabilities of neutrophils determined with phagocytosable probes. J. Biol. Chem. 272:32767-32772.

40. Sandhu, J.K., Privora, H.F., Wenckebach, G., and Birnboim, H.C. 2000. Neutrophils, nitric oxide synthase, and mutations in the mutatect murine tumor model. Am. J. Pathol. 156:509-518.

41. Klebanoff, S.J., and Nathan, C.F. 1993. Nitrite production by stimulated human polymorphonuclear leukocytes supplemented with azide and catalase. Biochem. Biophys. Res. Commun. 197:192-196.

42. Yan, L., Vandivier, W., Suffrendini, A.F., and Danner, R.L. 1994. Human polymorphonuclear leukocytes lack detectable nitric oxide synthase activity. J. Immunol. 153:1825-1834.

43. Daugherty, A., Dunn, J.L., Rateri, D.L., and Heinecke, J.W. 1994. Myeloperoxidase, a catalyst for lipoprotein oxidation, is expressed in human atherosclerotic lesions. J. Clin. Invest. 94:437-444.

44. Leeuwenburgh, C., et al. 1997. Reactive nitrogen intermediates promote low density lipoprotein oxidation in human atherosclerotic intima. J. Biol. Chem. 272:1433-1436.

45. Podrez, E.A., Schmitt, D., Hoff, H.F., and Hazen, S.L. 1999. Myeloperoxidase-generated reactive nitrogen species convert LDL into an atherogenic form in vitro. J. Clin. Invest. 103:1547-1560.

46. Hazen, S.L., and Heinecke, J.W. 1997. 3-Chlorotyrosine, a specific marker of myeloperoxidase-catalyzed oxidation, is markedly elevated in low density lipoprotein isolated from human atherosclerotic intima. J. Clin. Invest. 99:2075-2081.

47. Tsai, W.C., et al. 1997. Nitric oxide is required for effective innate immunity against Klebsiella pneumoniae. Infect. Immun. 65:1870-1875.

48. Miyoshi, S., and Shinoda, S. 2000. Microbial metalloproteases and pathogenesis. Microbes Infect. 2:91-98. 